\title{
Korean Evidentials and Assertion
}

\author{
Kyung-Sook Chung \\ Simon Fraser University
}

\section{Introduction}

Sentences with the Korean suffix -te express evidentiality (Sohn 1994, Cinque 1999). For example, (1a) conveys the direct evidential meaning that the speaker witnessed the event, and thus contrasts with the non-evidential sentence that lacks -te in (1b), which does not convey the evidential meaning.

$\begin{array}{ll}\text { a. } & \text { phyenci-lul } \\ \text { Mary-NOM } & \text { letter-ACC }\end{array}$

'[I saw] Mary was writing a/the letter.'
b. mary-ka phyenci-lul
Mary-NOM letter-ACC

'Mary was writing a/the letter.' ssu-te-la.

write-S.PAST-DEC

ssu-ko iss-ess-ta.

write-PROG-PFCT-DEC

In addition, it has also been noted that, unlike non-evidential sentences like (1b), sentences like (1a) imply abstract concepts regarding the speaker's attitude such as 'psychological distance', 'weakened reliability' (Shin 1980), and 'lack of responsibility' (Kim 1981). Such meanings are unexpected since direct evidentiality indicates the speaker's witness and should convey that the proposition in question is more reliable and trustworthy and hence the speaker feels certain about it (Willett 1988).

The issue of this paper is: How can the two aspects of meaning conveyed by -te sentences be reconciled? My claim is that, in Korean evidentials, the speaker relates the speaker's association to the information without believing or making a commitment to it. To capture this in formal terms, I propose that a Korean evidential sentence (direct or indirect) does not express an assertive speech act but rather a presentative speech act, in the sense of Faller (2002). In section 2, I illustrate different types of evidentials in Korean. In section 3, I show that Korean evidential sentences (direct or indirect) are not assertive and that the speaker of an evidential sentence simply serves as a channel through which the proposition is obtained and delivered to the hearer. Section 4 discusses Faller's (2002) analysis of Quechua evidentials, particularly her analysis of the reportative form -si as a presentative speech act operator. In section 5, I argue that a presentative speech act is what crucially distinguishes evidential sentences from non-evidential sentences in Korean and propose a new sincerity condition for the presentative speech act for Korean evidential sentences. My conclusions are given in section 6 .

\section{Evidentials in Korean}

Evidentiality is a grammatical category indicating the source of the information-for example, whether the speaker has personally seen (or perceived) the situation in question, inferred it from evidence, or heard it from other people. Korean has four types of evidentiality: a direct evidential, two inferential indirect evidentials (one based on the result state of a prior event and one based on the speaker's reasoning), and a reportative (or hearsay) evidential (Chung 2005). I will focus mainly on the direct and inferential indirect evidentials in this section because in Faller's analysis of Quechua evidentials, only reportatives are non-assertive, whereas in Korean, not only reportatives but also direct and inferential indirect evidentials exhibit non-assertive speech acts, as will be discussed in section 3 .

\footnotetext{
* I would like to thank Donna Gerdts and Lisa Matthewson for their helpful comments and discussion. I also thank the WCCFL audience for their comments. All remaining shortcomings are my own.
} 
The suffix -te refers to the speaker's perceptual field in the past reference time. I define -te as the spatial deictic past tense in Chung (2004, 2005). Unlike regular tenses, -te requires reference not only to time but also to space, i.e. the speaker's perceptual field, and thereby induces an evidential environment. ${ }^{1}$ A sentence with -te, in the absence of other tense, aspect, and mood marker, expresses a direct evidential meaning, i.e. that the speaker witnessed (or perceived) the event, as shown in (2).
a. $\mathrm{ku}$ tangsi
john-i
ce cip-ey
sal-te-la.
that time
John-NOM
that house-LOC
live-S.PAST-DEC

'[I saw] John was living in that house at that time.'
b. *ku tangsi
shakespeare-ka
ce cip-ey
sal-te-la.
that time
Shakespeare-NOM
that house-LOC
live-S.PAST-DEC

'[I saw] Shakespeare was living in that house at that time.'

Example (2a) indicates that the speaker witnessed John's living at the house. Example (2b) is unacceptable because it is impossible for a speaker who is not a contemporary to Shakespeare to witness him living in the house.

In the presence of the suffixes -ess or -keyss, a sentence with -te expresses an inferential indirect evidential meaning. With -ess, a suffix denoting the perfect, (3a) containing -te is an indirect evidential sentence that conveys the speaker's inference based on the result state of a prior event; compare (3b) without -te, which is simply a perfect sentence (Chung 2005, in press).
a. john-i
pheyenci-lul
John-NOM letter-ACC
ssu-ess-te-la.
b. john-i
John-NOM
pheyenci-lul
'John has written/wrote a/the letter.'
ssu-ess-ta.
write-PFCT-DEC write-PFCT-S.PAST-DEC

'[I inferred] John wrote a/the letter.' Or 'John apparently wrote a/the letter.'

Thus (3a) indicates that although the speaker did not witness the event of John's writing a letter, (s)he inferred the event based on the result state-for example, a letter that was already written at the past reference time. With -keyss, a modal suffix denoting 'possibility' (or 'weak necessity'), (4a) with -te is an evidential sentence that conveys the speaker's inference based on his or her reasoning; compare (4b) without -te, which is a non-evidential modal sentence.
(4) a. john-i
hoycang-i
toy-keyss-te-la.
John-NOM
president-NOM
become-MOD-S.PAST-DEC
'[I inferred] John would become the president.'
b. john-i
hoycang-i
toy-keyss-ta.
John-NOM
president-NOM
become-MOD-DEC
'John will become the president.'

\section{Non-assertive Korean evidentials}

\subsection{Restrictions on matrix verbs}

In what follows, I show, based on the restrictions that pertain to evidential sentences, that Korean evidential sentences are not assertive. First, the suffix -te exhibits a restriction with respect to matrix verbs. Evidential sentences with -te are allowed as a complement of the verb say, but not as a

\footnotetext{
${ }^{1}$ In addition, I argue that there is a present counterpart of $-t e$, the spatial deictic present tense $-n e y$, which also induces an evidential environment in Korean (Chung 2005).
} 
complement of other attitude verbs like believe and assert, as illustrated in (5a) and (5b). In contrast, non-evidential sentences have no such restrictions (see (5c)).
a. mary-nun
john-i
pheynci-lul ssu-te-la-ko
malha-yss-ta.
Mary-TOP
John-NOM
letter-ACC write-S.PAST-DEC-COMP
say-PFCT-DEC
'Mary said that [she saw] John was writing a/the letter.'
b. \#mary-nun john-i pheynci-lul ssu-te-la-ko
Mary-TOP John-NOM letter-ACC write-S.PAST-DEC-COMP
mit-ess-ta./ tanenha-yss-ta.
believe-PFCT-DEC/ assert-PFCT-DEC
'Mary believed/asserted that [she saw] John was writing a/the letter.'
c. mary-nun john-i pheynci-lul ssu-ko iss-ess-ta-ko
Mary-TOP John-NOM letter-ACC write-PROG-PFCT-DEC-COMP

mit-ess-ta./ tanenha-yss-ta.
believe-PFCT-DEC/ assert-PFCT-DEC
'Mary believed/asserted that John was writing a/the letter.'

Inferential indirect evidential sentences are also not allowed as complements of attitude verbs, such as mit 'believe' and tanenha 'assert': the non-evidentials (6a) and (7a) are fine but the evidentials $(6 b)$ and $(7 b)$ are not.

(6)
a. mary-nun john-i
Mary-TOP John-NOM
pheynci-lul
ssu-ess-ta-ko
mit-ess-ta./
letter-ACC
write-PFCT-DEC-COMP
believe-PFCT-DEC/ assert-PFCT-DEC
'Mary believed/asserted that John wrote a/the letter.'
b. \#mary-nun john-i
Mary-TOP John-NOM
mit-ess-ta./ tanenha-yss-ta.
believe-PFCT-DEC/ assert-PFCT-DEC
ssu-ess-te-la-ko
write-PFCT-S.PAST-DEC-COMP
'Mary believed/asserted that John wrote/had written a/the letter.'

(7)
a. mary-nun john-i
Mary-TOP
mit-ess-ta./
believe-PFCT-DEC/
John-NOM
hoycang-i
toy-keyss-ta-ko
president-NOM
become-MOD-DEC-COMP
tanenha-yss-ta.
'Mary believed/asserted that John would become the president.'
b. \#mary-nun john-i hoycang-i toy-keyss-te-la-ko
Mary-TOP John-NOM president-NOM become-MOD-S.PAST-DEC-COMP
mit-ess-ta./ tanenha-yss-ta.
believe-PFCT-DEC/ assert-PFCT-DEC
'Mary believed/asserted that John would become the president.'

Sentence (7a) indicates the speaker's assertion about the probability of the proposition Mary becomes the president, whereas in (7b), the speaker simply presents the probability of the proposition based on his or her reasoning without asserting it. Thus the incompatibility with attitude verbs like believe and assert indicates that, unlike non-evidential sentences, evidential sentences with -te lack the speaker's belief in the proposition conveyed. 


\title{
3.2. Condition on -te sentences
}

Another argument that evidential sentences are not assertive comes from a special condition on -te sentences, specifically a restriction on the speaker: the speaker should be a passive perceiver, not an active participant in the event described by the sentence. So when the speaker plays a voluntary agentive role in the event, the sentence is unacceptable, as illustrated in (8)-(10).
a. mary/??na(y)-ka/-nun
phiano-soli-lul
tut-te-la.
Mary/I-NOM/-TOP piano-sound-ACC
hear-S.PAST-DEC
'[I noticed] Mary/I heard a piano.'
b. na(y)-ka/-nun
I-NOM/-TOP
phiano-soli-ka
piano-sound-NOM
'[I noticed] I heard a piano.'

\author{
tul-li-te-la. \\ hear-PASSIVE-S.PAST-DEC
}

When the subject is third person, there is no restriction concerning the use of -te. However, with firstperson subjects, the use of -te is restricted. In (8a), the first-person subject is the agent of a transitive clause-as evidenced by the fact that the predicate tut 'hear' assigns the accusative case marker -luland the sentence is unacceptable. In contrast, $(8 \mathrm{~b})$ is acceptable because the first-person subject is not an agent - as evidenced by the nominative case marker on the object and the passive morpheme on the predicate. The same thing is true of the examples in (9):
a.??na(y)-ka/na-nun
ku-uy mal-ul
he-GEN word-ACC understand-COMP
mos-ha-te-la.
I-NOM/I-TOP
'[I noticed] I did/could not understand what he said.'
b. na(y)-ka/na-nun ku-uy mal-i ihay(-ka) an-toy-te-la. I-NOM/I-TOP he-GEN word-NOM understanding-NOM NEG-become-S.PAST-DEC
'[I noticed] I did/could not understand what he said.'

The first-person subject of (9a) is the agent of a transitive clause in which the predicate ihayha 'understand' (literally translated as 'do understanding') assigns the accusative case marker -lul, whereas the predicate toy 'become' of (9b) is intransitive.

We see this difference with an unergative predicate versus an unaccusative predicate in (10):
a. ??na(y)-ka/nun wul-te-la.
I-NOM/TOP cry-S.PAST-DEC
'[I noticed] I was crying.'
b. na(y)-ka/nun nwunmwul-i nao-te-la.
I-NOM/TOP tear-NOM come.out-S.PAST-DEC
'[I noticed] I had tears coming to/out of my eyes.'

In the unacceptable sentence (10a) the first-person subject is the agent of the unergative predicate wul 'cry', whereas in the acceptable sentence $(10 \mathrm{~b})$ the first-person subject is not an agent since the predicate nao 'come out' is unaccusative. We see that a sentence with -te is unacceptable when the speaker plays an agentive role in the event described by the sentence. In contrast, non-evidential sentences do not exhibit such restrictions. This is because a speaker's own actions or appearances are 
usually not a target of his or her passive perception, while non-evidential sentences do not involve the speaker's passive perception. ${ }^{2}$

To sum up, when the speaker utters an evidential sentence (direct or indirect), (s)he objectively conveys the proposition that refers to a state of affairs that is perceived through his or her senses. ${ }^{3}$ This indicates that the speaker of an evidential sentence is not the person that is actively involved in making a judgment about the proposition, but simply serves as a channel through which the proposition is obtained and delivered to the hearer. ${ }^{4}$ This means that the speaker is neutral about his (her) attitude toward or belief in the proposition, which explains why the direct evidential sentence (1a) expresses those abstract concepts regarding the speaker's attitude ('psychological distance', 'weakened reliability', and 'lack of responsibility') mentioned above. Thus, Korean evidential sentences do not express assertive speech acts. ${ }^{5}$

\section{Faller's (2002) Presentative Speech Act}

The three Cuzco Quechua enclitics, -mi, -si, and -chá, have been analyzed as evidential markersrespectively, a direct evidential, a reportative, and a conjecture (based on the speaker's reasoning). ${ }^{6}$ Faller (2002) analyzes evidentiality (in any language) within speech act theory. She argues that the three enclitics above are illocutionary operators (or modifiers of the sincerity condition) in the sense of the speech act theory developed by Searle and Venderveken (1985).

According to Faller, - $m i$ is an illocutionary operator that modifies the sincerity condition of simple speech acts by adding the condition that the speaker sees the event described by the sentence, which is illustrated in the comparison between the simple assertive sentence (11a) and the direct evidential sentence with -mi (11b):

(11) a. Para-sha-n.

rain-PROG-3

$$
\begin{aligned}
& p=\text { 'it is raining.' } \\
& \mathrm{ILL}=\operatorname{ASSERT}(p) \\
& \operatorname{SINC}=\{\operatorname{Bel}(s, p)\} \\
& \text { STRENGTH }=0
\end{aligned}
$$

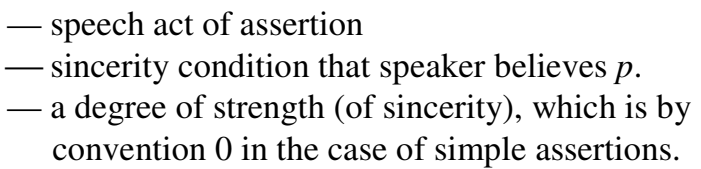

${ }^{2}$ In fact, the notion of active participant is not equivalent to the notion of the thematic role agent. The first-person subject of (i) is an agent, yet it is acceptable if the speaker suddenly realized (perceived) what (s)he was doing.

$$
\begin{array}{llcccl}
\text { na-to } & \text { molu-key } & \text { (nay-ka) } & \text { ku-uy } & \text { cip-ulo } & \text { kele-ka-te-la. } \\
\text { I-even } & \text { not.know-ADV } & \text { I-NOM } & \text { he-GEN } & \text { house-toward } & \text { walk-go-S.PAST-DEC } \\
\text { '[I noticed] I was walking toward his house without knowing it/unconsciously.' } & \text { (Gim } & \text { 1980:77) }
\end{array}
$$

Sentences like (i) become acceptable when they are used to describe the speaker's action or appearance as if it were somebody else's, i.e. in a detached way as an observer of his or her own action or appearance. This can be explained by the notion of passive perception. So even if the speaker is the agent of the event, -te is allowed as long as a speaker's own action is unconscious or involuntary so that the action can be a target of his or her passive perception. For details, see Chung $(2004,2005)$.

${ }^{3}$ The perception involves not only the visual sense but also non-visual senses: hearing, touch, taste, smell, or any kind of intellectual experience.

${ }^{4}$ Faller (2002:198) uses this term 'channel' to analyze the Quechua reportative form -si.

${ }^{5}$ This claim can be further supported by the fact that $-t e$ can occur in questions.

${ }^{6}$ The three enclitics occupy the same morphological slot, encode an evidential value, and have the same distributional properties (Faller 2002:184). 
b. Para-sha-n-mi ${ }^{7}$

Rain-PROG-3-MI

$p=$ 'it is raining.'

$\mathrm{EV}=$ speaker sees that $p$

$\mathrm{ILL}=\operatorname{ASSERT}(p) \quad$ - speech act of assertion

$\mathrm{SINC}=\left\{\operatorname{Bel}(s, p), \operatorname{See}\left(s, e_{p}\right)\right\} \quad$ - speaker's belief is justified by the fact that the speaker

STRENGTH $=+1 \quad$ sees the event $e$ described by $p$, i.e. (s)he sees that it is raining.

$$
\begin{aligned}
& s=\text { Speaker } \\
& h=\text { Hearer } \\
& p=\text { Proposition } \\
& \text { ILL = Illocutionary Force } \\
& \text { SINC = Sincerity Condition }
\end{aligned}
$$

Adding - $m i$ to the simple assertive sentence (11a) has the effect of adding a sincerity condition, which is a higher order predicate See justifying the speaker's belief. This means that the speaker has the best possible grounds for making the speech act. A side effect of adding this justification condition is that the strength of the assertion (that is, strength of sincerity) is increased by 1 , as shown in (11b). Thus, - $m i$ is a function that takes the illocutionary act associated with simple assertions as its argument and outputs the illocutionary act of assertion with the added sincerity condition, as illustrated in (12):

$$
\begin{array}{ll}
-\boldsymbol{m i}: & \operatorname{ASSERT}(p) \\
& \operatorname{SINC}=\{\operatorname{Bel}(s, p)\}
\end{array}
$$

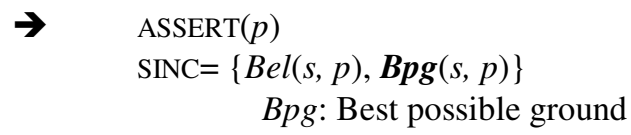

On the other hand, the reportative enclitic -si, according to Faller, does not have the sincerity condition of an assertion, namely that the speaker believes the proposition in question. So Faller proposes a new type of speech act-'presentation'-because -si indicates that the speaker brings another speaker's assertion into the conversation, i.e. presentation of another speaker's assertion, as illustrated in (13):

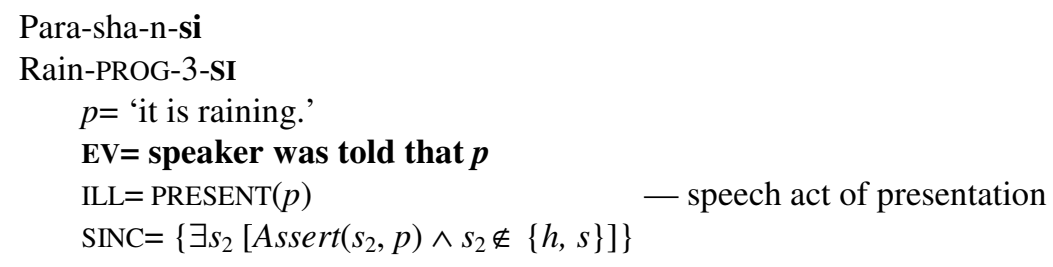

The enclitic -si introduces a new sincerity condition such that there is some speaker who asserted $p$, and this speaker is neither the hearer nor the current speaker, and this condition does not include the speaker's belief in $p$. This means that $-s i$ changes a speech act of assertion (made by a person other than the actual speaker) into another speech act of 'presentation' (made by the actual speaker). Hence, $-s i$ is a function from a speech act to a speech act, and thus, applies to a speech act of assertion, yielding a speech act of presentation. These are illustrated in (14):

$$
\text { ssi: } \quad \begin{aligned}
& \operatorname{ASSERT}(p) \\
& \\
& \operatorname{SINC}=\{\operatorname{believe}(s, p)\}
\end{aligned}
$$

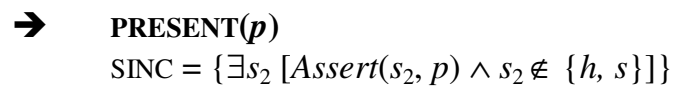

\footnotetext{
${ }^{7}$ For the enclitic - $m i$, according to Faller (2002), the meaning of direct evidence is a part of a wider concept that includes cases where the speaker obtained the information from a source of authority (e.g. teachers or books). The difference between (11a) and (11b) is that (11a) implicates that the speaker has the best possible evidence (e.g. speaker's witness) but (11b) grammatically encodes that the speaker has the best possible evidence.
} 


\section{An analysis of Korean evidentials}

I have shown that there is a clear difference between Korean evidential and non-evidential sentences in terms of the speaker's belief in (or commitment to) the truth of the proposition in question. If the speaker has belief in (and is certain about) the proposition, (s)he will use a non-evidential sentence like (1b). In contrast, if the speaker lacks or wants to underspecify his (her) belief, (s)he will use an evidential sentence like (1a). Thus, I argue that the speech act is the basic difference that lies between evidential sentences and non-evidential sentences in Korean.

According to Faller (2002), evidentials are basically illocutionary operators, i.e. modifiers of the sincerity conditions associated with a speech act. ${ }^{8}$ This idea could apply to Korean evidentials because Korean evidential sentences exhibit a difference in the speech act, as compared with non-evidential sentences. However, all the evidential sentences-not only Korean reportative sentences, but also Korean direct and inferential indirect evidential sentences-express non-assertive speech acts, i.e. presentative speech acts. This presentative speech act is what distinguishes evidential sentences from non-evidential sentences in Korean. The different speech act types between Quechua and Korean are shown in Table 1:

\begin{tabular}{|r|c|c|}
\hline & QUECHUA & KOREAN \\
\hline NON-EVIDENTIAL & assertion & assertion \\
\hline DIRECT EVIDENTIAL & assertion & presentation \\
\hline INFERENTIAL INDIRECT EVIDENTIAL & assertion & presentation \\
\hline REPORTATIVE INDIRECT EVIDENTIAL & presentation & presentation \\
\hline
\end{tabular}

Table 1: Different speech act types of evidentials

Thus, the problem with Faller's (2002) analysis is that the meaning of the presentative speech act given in (14) might work for the Korean reportative evidentials but cannot work for the non-reportative evidentials because all the Korean evidentials (including even direct evidentials) express a presentative speech act. Basically, Korean evidentials do two things - convey an evidential meaning, i.e. the source of information that the speaker acquires, and express the non-assertive mode, i.e. a presentative speech act. This view also differs from Faller's (2002) view on evidentiality. She claims that evidential meanings (direct or indirect) operate on the level of speech acts only. In contrast, I argue that different evidential meanings operate on the level of tense/aspect/mood and, in addition, that all the evidentials converge on the level of speech acts as a presentative speech act. ${ }^{9}$

One additional point in favor of Korean evidentials being presentative speech acts comes from the fact that, unlike non-evidential sentences, they always require the presence of the actual hearer and thus are rarely used in written texts. I argue that the speaker of an evidential sentence obtains a proposition through his/her senses and simply delivers it to the hearer without his/her commitment to it.

\footnotetext{
${ }^{8}$ The conjecture marker -chá, according to Faller (2002), is also an illocutionary operator, but it adds not only its evidential meaning (i.e. conjecture through reasoning) to the sincerity condition, but also its epistemic meaning to the propositional content.

(i) Para-sha-n-chá

Rain-PROG-3-chá

$q=$ 'it is raining.'

$p=\diamond q$

$\mathrm{ILL}=\operatorname{ASSERT}(\diamond q)$

$\operatorname{SINC}=\{\operatorname{Bel}(s, \diamond q), \boldsymbol{R e a}(s, \operatorname{Bel}(s, \diamond q))\}$

STRENGTH $=-1$

- speech act of assertion
- speaker believes that $p$ is an epistemic possibility
and that this belief is based on his or her own reasoning.
}

Faller represents the strength of the assertion as -1 because she takes the strength to be weaker than simple assertion due to the modalization of the preposition (Faller 2002: 184-188).

${ }^{9}$ Faller actually admits that her view is problematic for the conjecture marker -chá, which is, according to her, an epistemic modal as well as an illocutionary operator. 
In this respect, evidential sentences have a property of ditransitive predicates. I reinterpret the notion of presentation as the notion of ditransitivity. To capture the above facts, I propose the sincerity condition on the speech act of presentation in (15):

$\operatorname{PRESENT}(p): \operatorname{SINCERITY~CONDITION}=\{\operatorname{Give}(s, h, \exists v[\operatorname{Have}(s, v$ for $p)])\}$

$$
\begin{aligned}
& s=\text { Speaker } \\
& h=\text { Hearer } \\
& v=\text { Evidence } \\
& p=\text { Proposition }
\end{aligned}
$$

The condition in (15) says that the speaker $s$ simply delivers to the hearer $h$ the fact that (s)he has evidence $v$ of proposition $p$, and that the evidence can be direct, inferential indirect, or reportative indirect. The condition does not specify the speaker's belief in the proposition.

\section{Conclusion}

I have argued that a presentative speech act is what crucially distinguishes evidential sentences from non-evidential sentences in Korean. Consequently, the role of the speaker differs between the two types of sentences: the speaker serves as an active judgment-maker in regular sentences but as a passive channel through which the proposition is obtained and delivered to the hearer in evidential sentences. Thus, I have shown that Korean evidentials do two things- convey an evidential meaning, i.e. the source of information that the speaker acquires, and express the non-assertive mode, i.e. a presentative speech act.

Furthermore, evidential and non-evidential sentences differ in terms of the evaluation worldwhile the latter use the actual world, the former use the speaker's perceptual world. This has a further consequence in the interpretation of the perfect suffix -ess (see (3)): evidential sentences like (3a) are modal sentences, whereas non-evidential sentences like (3b) are non-modal (factive) statements.

Why is it that Korean evidential sentences are not assertive? Based on Lyons' (1977) distinction between subjective and objective epistemic modality, Nuyts (2001:385-393) claims that the notion of subjectivity and objectivity should be defined as a dimension of evidence-subjective evidence versus objective (or intersubjective) evidence, which is independent of epistemic modality. Subjective evidence indicates that only the speaker knows (or has access to) the evidence and draws a conclusion from it; objective evidence indicates that the evidence is known to (or accessible to) a larger group of people who share the same conclusion based on it. Using Nuyts' (2001) notion of speaker's subjective/objective epistemic evidence, I claim that evidential sentences make use of subjective evidence only, whereas non-evidential sentences make use of subjective and/or objective evidence. I suggest that Korean speakers use evidential sentences to be relieved of the burden of full responsibility for the claim made on subjective evidence alone.

One implication of my analysis is that evidentials in general may lack assertive speech acts. On the other hand, it is possible that the assertive mode is subsumed under the evidential system in some languages ${ }^{10}$ but not others, thus capturing a fundamental difference in the use and meaning of

\footnotetext{
${ }^{10}$ I think that Kashaya is one of those languages. Oswalt (1986) proposes the following evidential types for Kashaya:$$
\text { Performative }>\text { Factual-Visual }>\text { Auditory }>\text { Inferential }>\text { Quotative }
$$

According to Oswalt (1986:34-37), Kashaya not only distinguishes the auditory evidential from the visual (factual), but also the performative evidential from the visual (factual) evidential. The performative suffixes indicate that the speaker knows of what (s)he speaks because (s)he is performing the act himself/herself or has just performed it. The subject of clauses with performative suffixes is always a first person, as illustrated in (ii):
} 
evidentials across languages. A remaining question is: Is there any way to subsume this presentative mode under one of the traditionally established speech acts?

\section{References}

Chung, Kyung-Sook. 2004. The Korean suffix -te as spatio-temporal deictic tense. In Proceedings of the 23rd WCCFL, eds. Vineeta Chand, Ann Kelleher, Angelo J. Rodríguez and Benjamin Schmeiser, 140-153. Somerville, MA: Cascadilla Press.

Chung, Kyung-Sook. 2005. Space in Tense: The Interaction of Tense, Aspect, Evidentiality, and Speech Act in Korean. Ph.D. dissertation, Simon Fraser University.

Chung, Kyung-Sook. In press. Toward an integrated theory of the perfect and the indirect evidential. In Proceedings of NELS 36. University of Massachusetts, Amherst.

Cinque, Guglielmo. 1999. Adverbs and Functional Heads: A Cross-Linguistic Perspective. Oxford: Oxford University Press.

Faller, Martina. 2002. Semantics and Pragmatics of Evidentials in Cuzco Quechua. Ph.D. dissertation, Stanford University.

Gim, Cha-Kyun. 1980. Kwukesice hyengthaysouy uymi: Hoysang hyengthaysolul cwungsimulo (The semantics of Korean tense morphemes: With focus on the retrospective morpheme). Han-Geul 169:45-116.

Kim, Young-Hee. 1981. Hoysangmwunuy inchingceyakkwa chaykimseng (Person constraint on the retrospective sentences and responsibility). Hankwuhak (Korean Studies) 10:37-80.

Lyons, John. 1977. Semantics. Cambridge: Cambridge University Press.

Nuyts, Jan. 2001. Subjectivity as an evidential dimension in epistemic modal expressions. Journal of Pragmatics $33: 383-400$.

Oswalt, Robert L. 1986. The Evidential System of Kashaya. In Evidentiality: The Linguistic Coding of Epistemology, eds. Wallace Chafe and Johanna Nichols, 29-45. Norwood, New Jersey: Ablex Publishing Corporation.

Searle, John R., and Venderveken, Daniel. 1985. Foundations of Illocutionary Logic. Cambridge: Cambridge University Press.

Shin, Hyun-sook. 1980. -Tela-uy ssuimkwa uymi (The Meaning and Use of -tela), Kunkwuk University Nonmwuncip (Thesis Series) 11.

Sohn, Ho-Min. 1994. Korean. London: Routledge.

Willett, Thomas. 1988. A cross-linguistic survey of the grammaticization of evidentiality. Studies in Language 12:51-97.

(ii)
a. quwå.qala
'I am packing (a suitcase).'

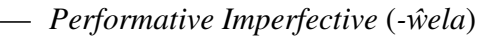
b. quwåhmela
'I just packed.'
- Performative Perfective (-mela)

In contrast, the factual suffix (imperfective) and the visual suffix (perfective) indicate that the speaker sees or saw the event described by the sentence (Oswalt 1986:35).
(iii) a. quwå.q $\mathrm{q}^{\mathrm{h}} \quad$ - Factual Imperfective $(-\hat{w} a)$
'[I see] he is packing.'
b. quwahy - Visual Perfective (-yă)
'[I just saw] he packed.'

In Korean, for the performative cases of Kashaya, non-evidential sentences would be used, whereas for the other types of evidentals in (i), evidential sentences would be used. 


\title{
Proceedings of the 25th West Coast Conference on Formal Linguistics
}

\author{
edited by Donald Baumer, \\ David Montero, and Michael Scanlon
}

Cascadilla Proceedings Project Somerville, MA 2006

\section{Copyright information}

Proceedings of the 25th West Coast Conference on Formal Linguistics

(C) 2006 Cascadilla Proceedings Project, Somerville, MA. All rights reserved

ISBN 1-57473-415-6 library binding

A copyright notice for each paper is located at the bottom of the first page of the paper.

Reprints for course packs can be authorized by Cascadilla Proceedings Project.

\section{Ordering information}

Orders for the library binding edition are handled by Cascadilla Press.

To place an order, go to www.lingref.com or contact:

Cascadilla Press, P.O. Box 440355, Somerville, MA 02144, USA

phone: 1-617-776-2370, fax: 1-617-776-2271, e-mail: sales@cascadilla.com

\section{Web access and citation information}

This entire proceedings can also be viewed on the web at www.lingref.com. Each paper has a unique document \# which can be added to citations to facilitate access. The document \# should not replace the full citation.

This paper can be cited as:

Chung, Kyung-Sook. 2006. Korean Evidentials and Assertion. In Proceedings of the 25th West Coast Conference on Formal Linguistics, ed. Donald Baumer, David Montero, and Michael Scanlon, 105-113. Somerville, MA: Cascadilla Proceedings Project.

or:

Chung, Kyung-Sook. 2006. Korean Evidentials and Assertion. In Proceedings of the 25th West Coast Conference on Formal Linguistics, ed. Donald Baumer, David Montero, and Michael Scanlon, 105-113. Somerville, MA: Cascadilla Proceedings Project. www.lingref.com, document \#1438. 